\title{
El BIC zona arqueológica Ibolca-Obulco-Obolcon-Bulkuna- Porcuna: Una realidad en continua tensión
}

\author{
Pablo Manuel Millán Millán | Universidad de Sevilla, Asociación ARQVIPO \\ Pablo Jesús Casado Millán | Universidad de Granada, Asociación ARQVIPO \\ Rafael Antonio Saco Montilla | Asociación ARQVIPO \\ Fernando Enrique Salas Herrera | Asociación ARQVIPO
}

URL de la contribución <www.iaph.es/revistaph/index.php/revistaph/article/view/3588>

En julio de 2014 como final de un proceso de veinticinco años de expediente (iniciado en 1989) se inscriben en el Catálogo General del Patrimonio Histórico Andaluz como bien de interés cultural, con la tipología de zona arqueológica, dieciocho yacimientos en Porcuna (Jaén). Con este hecho quedan protegidos con la máxima figura legal la mayoría de los principales yacimientos asociados al fenómeno urbano de la histórica ciudad de lbolcaObulco-Obolcon-Bulkūna-Porcuna y con mayor riesgo de alteración. La declaración supondrá para el municipio la protección de una extensión de 403 ha, de las cuales 100 ha serán de suelo urbano.

El expediente se culmina por la inevitable necesidad de ejecución de una sentencia sobre la expropiación de los restos monumentales romanos excavados entre 1987 y 1991 en el sector San Benito de Obvlco por el Proyecto Porcuna de Arqueología.

Cuestiones que no son atribuibles únicamente a la casualidad quieren que el inicio y finalización del expediente de BIC casi coincidan con dos momentos legales muy relevantes para el urbanismo de Porcuna. Por un lado, las Normas Subsidiarias de 1987-1988 con el inicio del expediente en 1989. Por otro, el nuevo Plan General de Ordenación Urbana aprobado el 11 de noviembre de 2014, apenas a cuatro meses de la declaración de la zona, aunque con una gestación del mismo de más de una década.

Sin embargo, este avenido matrimonio de tiempos entre urbanismo y patrimonio arqueológico ha sido sólo una apariencia, ya que escondía un divorcio -en esencia- de dos elementos que debieran ser indisociables al formar parte de una única realidad. Las secuelas muestran que la relación no se ha desarrollado en condiciones de complementariedad o equilibrio.

La sustitución de edificaciones históricas en las áreas urbanas y los nuevos crecimientos sin cautelas patrimoniales han proliferado exponencialmente en las tres últimas décadas, debido en gran medida al auge económico de una sociedad de pequeños propietarios agrícolas apoyados en el monocultivo industrializado del olivar. En el análisis patrimonial pormenorizado las realidades resultantes son dispares. En las manzanas de los antiguos arrabales del casco histórico han dominado las reformas parciales y la mayoría de las alteraciones del subsuelo arqueológico y de elementos patrimoniales emergentes son importantes pero limitadas. En las áreas del centro del casco histórico los reemplazamientos han sido muy numerosos y con ello han sido masivas las pérdidas de registro arqueológico y de elementos patrimoniales. Es oportuno destacar la laxitud en la protección de los conjuntos y edificios del catálogo de las antiguas NNSS 1987-1988. Los resultados de su aplicación muestran un panorama ciertamente desolador.

La traumática experiencia lleva a hacerse la pregunta de si el amplio y sólido desarrollo legal ahora alcanzado va a servir para proteger con eficiencia el patrimonio o la situación simplemente se va a reducir a meros procesos burocráticos en una Administración que se escuda en el adelgazamiento producido por la crisis para argumentar la falta de agilidad de los expedientes, posibilitando a los interesados la no aplicación o la timidez en la adopción de las medidas. 
Se reconoce un esfuerzo de los agentes implicados en la destrucción en demostrar la asociación del frenazo local en la construcción al paulatino aumento de la protección. Una pregonada propaganda simplista e interesada que ignora malintencionadamente la convergencia multifactorial de los vectores negativos sobre el desarrollismo y las condiciones de la crisis económica actual.

Los nuevos instrumentos legales, aparte de la fuerte carga punitiva que debe ser disuasoria, ponen de relieve muchas situaciones ineludibles que deben ser abordadas a la mayor brevedad. Desde la elaboración intensa y sistemática de un catálogo para el reciente PGOU que recoja el estado de la cuestión del patrimonio porcunés, hasta un profundo programa de divulgación extensiva que muestre al municipio el porqué de esta nueva legislación. Cuestiones que deben potenciar la autogestión evitando los tratamientos de periferia, incongruentes con la realidad patrimonial reconocida.

Así mismo, los nuevos marcos llevan a que órganos culturales e instituciones museísticas se manifiesten como auténticas reliquias del pasado. Un pasado que hay que tener presente pero que no debe lastrar ni repetirse. Por lo tanto, procede redefinir cuál será su futuro en este nuevo organigrama, dado que socialmente no se entiende que el desperdicio de los recursos haya dejado sin oportunidades a los que acceden a un nuevo estatus.

A escasos meses de la declaración no hay mucha perspectiva para hacer una valoración de lo que ha supuesto, aunque eso no le quita ni un ápice a lo que creemos debe suponer, pues en una realidad patrimonial tan estragada los esfuerzos tienen que ser por conocer y legar lo conservado.

No cabe duda de que un ejemplo como el de Porcuna nos obliga a replantearnos las herramientas. Desde el insostenible aparato burocrático hasta la gestión por parte de la Administración. Ahora más que nunca se hace necesario un ejercicio de realidad que valore los resultados alcanzados. Si hace treinta años, cuando se diseñaron las optimistas bases para la gestión de la conser-

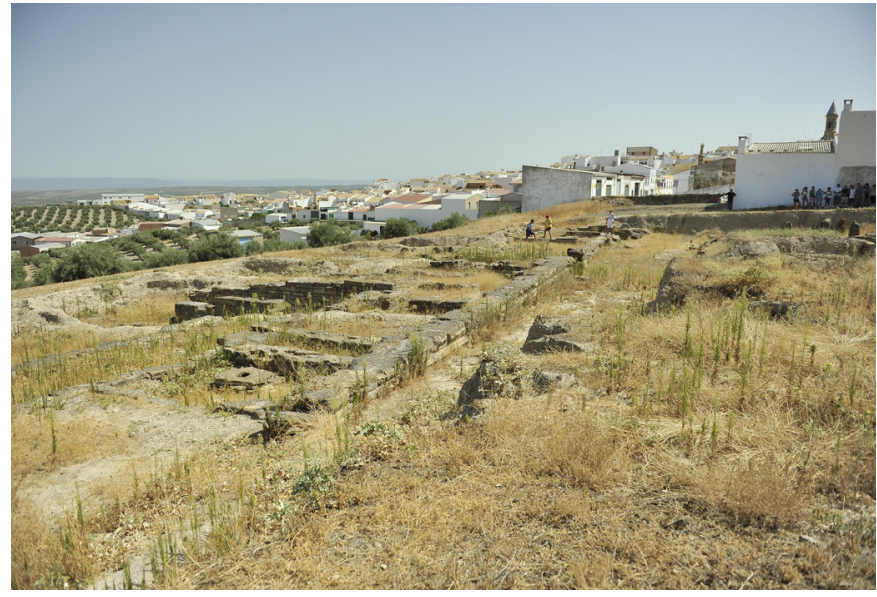

Yacimiento arqueológico en Porcuna (Jaén) | Alberto Gallego (https://www.flickr. $\mathrm{com} /$ photos/asociacioncontrapunto/)

vación patrimonial de la arqueología urbana se hubiera tenido un atisbo de estos resultados, se habría optado por mecanismos más sostenibles.

Partiendo del principio de que previa a la conservación es necesaria la concienciación social que reconozca en lo protegido un valor, hay que subrayar como en el caso de referencia no ha sido así, todo lo contrario. Las herramientas de conservación como el BIC han supuesto una confrontación social y la conservación un ejercicio de imposición y por tanto de inadaptación, hecho inequívoco de que el sistema no ha funcionado. Pese a ello, la última oportunidad que se abre aboca a la esperanza y por tanto lo seguiremos intentando. 